\title{
Characterization of nuclear fuels by ICP mass-spectrometric techniques
}

\author{
Ines Günther-Leopold • Niko Kivel • \\ Judith Kobler Waldis • Beat Wernli
}

Received: 19 July 2007 /Revised: 14 September 2007 / Accepted: 18 September 2007 / Published online: 9 October 2007

(C) Springer-Verlag 2007

\begin{abstract}
Isotopic analyses of radioactive materials such as irradiated nuclear fuel are of major importance for the optimization of the nuclear fuel cycle and for safeguard aspects. Among the mass-spectrometric techniques available, inductively coupled plasma mass spectrometry (ICPMS) and thermal ionization mass spectrometry are the most frequently applied methods for nuclear applications. Because of the low detection limits, the ability to analyze the isotopic composition of the elements and the applicability of the techniques for measuring stable as well as radioactive nuclides with similar sensitivity, both mass-spectrometric techniques are an excellent amendment to classical radioactivity counting methods. The paper describes selected applications of multicollector ICP-MS in combination with chromatographic separation techniques and laser ablation for the isotopic analysis of irradiated nuclear fuels. The advantages and limitations of the selected analytical technique for the characterization of such a heterogeneous sample matrix are discussed.
\end{abstract}

Keywords Inductively coupled plasma mass spectrometry . High-performance liquid chromatography · Laser ablation . Nuclear fuel $\cdot$ Isotope ratios $\cdot$ Fission products

\section{Introduction}

The characterization of nuclear fuel cycle materials for longlived radionuclides, such as fission products and actinides, is

I. Günther-Leopold $(\varangle) \cdot$ N. Kivel $\cdot$ J. Kobler Waldis $\cdot$ B. Wernli Laboratory for Materials Behaviour, Department of Nuclear Energy and Safety Research, Paul Scherrer Institut, 5232 Villigen PSI, Switzerland

e-mail: ines.guenther@psi.ch of interest for the nuclear industry and safeguard officials. For instance, the determination of the isotopic composition is essential in nuclear waste management, owing to long radioactive half-lives, high radiological toxicity and criticality concerns. Moreover, actinide isotope determinations are necessary for waste classification purposes and when new types of fuels and/or reactor operating conditions are investigated. Therefore, the main objective of various international programs dealing with postirradiation examinations (PIE) is focused on improving knowledge of the inventories of actinides, fission and neutron activation products in spent nuclear fuels [1]. The determination of trace amounts of these elements (concentration and isotopic composition) provides a relevant database for the validation of theoretical models and is of major importance for fuel licensing, safety studies, nuclear forensics, increasing the fuel enrichment for power reactors and for the storage of nuclear waste in geological repositories.

Radioactive isotopes like actinides and most of the fission products in nuclear fuel are traditionally quantified by means of radioactivity counting techniques $(\alpha, \beta, \gamma)$. However, these methods often require extensive matrix separation and sample purification before the identification of specific isotopes and the determination of their relative abundance is possible. Therefore, different mass-spectrometric techniques (such as glow discharge, secondary ion, laser ionization, thermal ionization or inductively coupled plasma mass spectrometry, ICP-MS) were established for the characterization of nuclear materials. Advantages are the low detection limits for a large number of elements combined with the ability to analyze the isotopic composition of the elements and the applicability of the techniques for measuring stable as well as radioactive nuclides with similar sensitivity. Among these techniques, ICP-MS and thermal ionization mass spectrometry (TIMS) are the most frequently applied methods and are also used for 
routine measurements in the nuclear industry [2-7]. For example, the American Society for Testing and Materials (ASTM) has developed and published ICP-MS atom counting standard methods for the determination of many long-lived actinides and their daughter products [8-11]. Beside the wellestablished techniques of sector-field and quadrupole-based ICP-MS (with or without collision/reaction cells) multicollector (MC) ICP-MS has gained much attention in the last few years owing to the significant increase in precision of the isotopic measurements combined with high sample throughput. Therefore and owing to the access to a wide variety of elements, MC-ICP-MS is starting to complement the commonly used technique of TIMS [12-16].

Typical applications of ICP-MS described in the accessible literature for nuclear fuel cycle materials have been the characterization of radioactive waste glasses [17], the determination of fission products in leachates and dissolver solutions of spent fuel $[18,19]$, process and quality control for actinides in pyrochemical partitioning processes [20], half-life determinations of radionuclides [21] and the characterization of solutions generated from corrosion testing of spent nuclear fuel under simulated geological conditions [22].

Numerous isobaric overlaps restrict the direct determination of many fission products and actinides by ICP-MS and because of the unknown isotopic composition of the sample these interferences cannot be corrected mathematically; therefore, extensive chemical separations are crucial for these elements [23]. In order to simplify the sample preparation procedure for highly radioactive samples, the method of online coupling of liquid chromatographic separation systems to overcome isobaric interferences in nuclear fuel samples was proposed in the early 1990s. These hyphenated techniques were developed and applied in different laboratories [24-26]. The online coupling with chromatographic separation devices (ion chromatography or high-performance liquid chromatography, HPLC) allowed the resolution of the isobaric interferences of fission products such as $\mathrm{Rb}, \mathrm{Sr}, \mathrm{Cs}$, lanthanides and actinides [27-33]. Beside chromatographic separations of interfering elements, the successful use of chemical cell ICP-MS technology has also been reported for interference reduction of $\mathrm{U} / \mathrm{Pu}[34,35]$ and $\mathrm{Sr} / \mathrm{Zr}$ [36].

Among the characterization of spent nuclear fuel itself, the investigation of the materials behavior of the fuel cladding and the reactor internals under irradiation is also of relevance for safety reasons. In order to obtain spatial information on all types of nuclear fuel cycle materials, which is not possible when samples have to be dissolved before an analysis, coupling and adaptation of commercial laser ablation (LA) systems for the direct analysis of radioactive materials have been successfully realized in few hot laboratories [37, 38]. LA-ICP-MS offers the advantages of high spatial resolution, low sample preparation, low limits of detection and good quantification capabilities. In the last couple of years, significant progress has been achieved in improving the sensitivity of the LA-ICP-MS technique and various quantification strategies have been reported [39]. Therefore, the use of LA-ICP-MS for the characterization of nuclear fuel cycle materials offers significant advantages and the first applications of this technique providing new insights into the behavior of nuclear fuels under irradiation have recently been reported [40].

The origin of the PIE experiments for light water reactor fuel at the Paul Scherrer Institut (PSI) dates back to the early 1980s. Since that time the analytical tools for nondestructive and destructive investigations of irradiated nuclear fuels have grown continuously and involve today MC-ICP-MS, LA-MC-ICP-MS, gamma spectrometry, profilometry, oxide thickness measurements, electron probe microanalysis (EPMA), secondary ion mass spectrometry (SIMS), scanning and transmission electron microscopy and other mechanical testing equipment. This paper provides an overview of various applications of ICP-MS in combination with HPLC as a separation technique and LA-MC-ICP-MS for the investigation of nuclear fuel cycle materials at the PSI hot laboratory. Examples for burn-up and fission product analysis as well as the determination of actinide isotope ratios are discussed in detail.

\section{Experimental}

\section{Sample preparation}

The radioactive nature of the material requires special equipment for sample preparation and for the analysis of nuclear fuel samples, which is realized by working in shielded hot cells or glove boxes. The apparatus for the dissolution of nuclear fuel samples which is installed in a hot cell is shown schematically in Fig. 1. Typically, 1-cm-long irradiated segments of $\mathrm{UO}_{2}$ or mixed oxide (MOX) fuels are cut in hot cells from the entire fuel rods and dissolved under reflux using $8 \mathrm{M} \mathrm{HNO}_{3}$ (VLSI, Fluka) at about $170{ }^{\circ} \mathrm{C}$ for $4 \mathrm{~h}$. A vacuum pump transports the escaping gases through three gas-washing bottles and a filter. The first two bottles are filled with $4 \mathrm{M} \mathrm{NaOH}$ solution in order to retain the released iodine, whereas the third bottle is empty and protects the filter and the pump from the $\mathrm{NaOH}$ solution. After filtration of the slightly soluble residues, stock solutions of the fuel samples are prepared by dilution with $1 \mathrm{M} \mathrm{HNO}_{3}$ up to a concentration of about $0.5 \mathrm{mg}$ fuel per gram of solution. Typically about $1-2 \%$ of the fuel sample is slightly soluble in nitric acid. This residue mostly consists of refractory elements like Mo, $\mathrm{Ru}$ and $\mathrm{Rh}$. For isotope dilution analyses, aliquots of the stock solutions are mixed with suitable spike isotope 


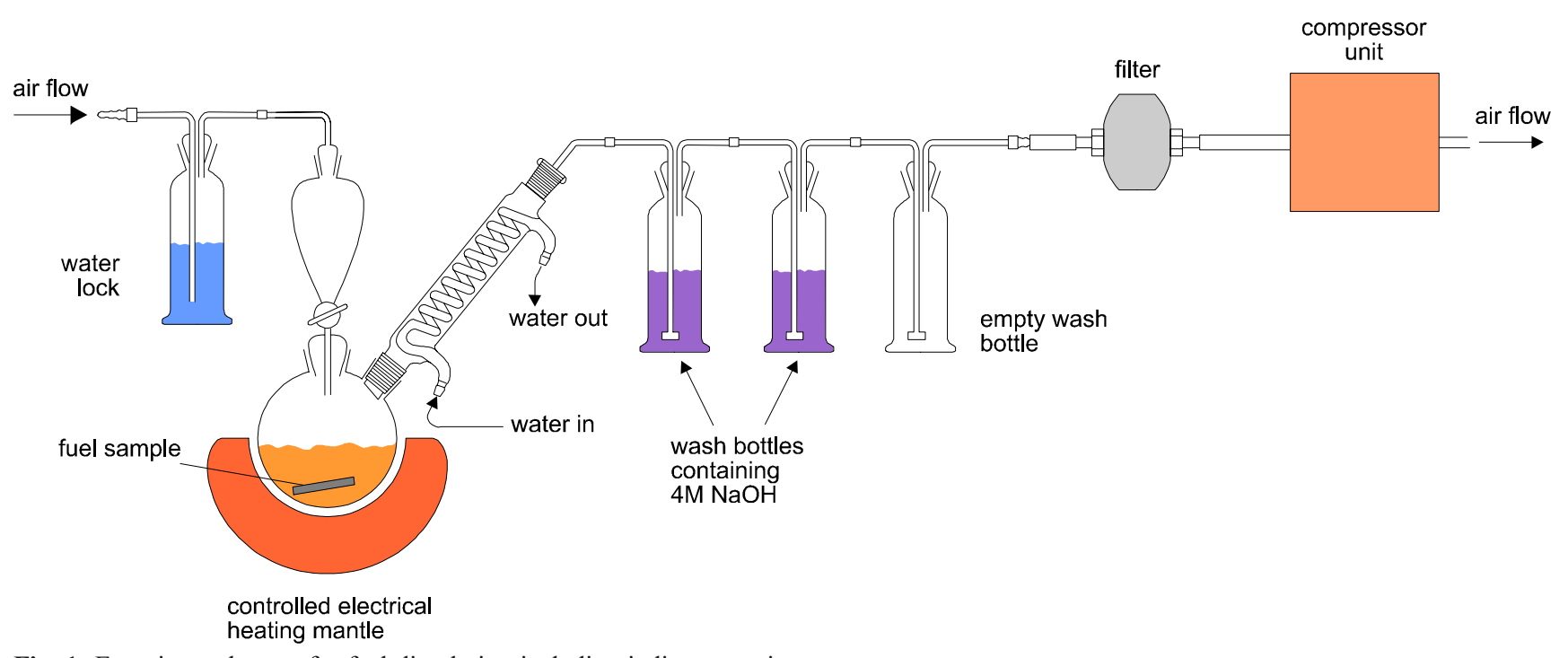

Fig. 1 Experimental setup for fuel dissolution including iodine capturing

reference materials $\left({ }^{233} \mathrm{U}\right.$-enriched spike IRMM-040a, ${ }^{242} \mathrm{Pu}-$ enriched spike IRMM-049c and ${ }^{150} \mathrm{Nd}$-enriched spike from ORNL) and diluted with $1 \% \mathrm{HNO}_{3}$ up to a concentration that can be measured by HPLC-ICP-MS. A further set of aliquots is directly diluted with $1 \% \mathrm{HNO}_{3}$ without spike addition.

High-performance liquid chromatography

A HPLC system (DX600 GS50, Dionex, Switzerland) equipped with IonPac 2-mm CS5A, CS12A (Dionex, Switzerland) or Gemini C18 ion-pair (Phenomenex, Germany) analytical columns is partly encapsulated in a glove box together with the ICP-MS sample-introduction system. The technical details of the chromatographic system, the mobile phases used, the chromatographic separation conditions and the online coupling to the ICPMS system have been described elsewhere [25, 41]. The flow rate of the HPLC system is adjusted between 0.25 and $0.40 \mathrm{~mL} / \mathrm{min}$ and the injection valve is equipped with a sample loop of $10 \mu \mathrm{L}$.

\section{Laser ablation}

The special demands on a LA system for the analysis of highly radioactive materials include permanent shielding of the samples. Therefore, a custom-built LSX 3700 LA system (Nukeuss, Cetac Technologies, Omaha, USA), which is based on a frequency-quadrupled Brilliant $\mathrm{B} \mathrm{Nd}$ : YAG solid-state laser, is used. The laser system provides a pulse width of $6 \mathrm{~ns}$, a repetition rate of $0.5-10 \mathrm{~Hz}$ and allows output energies up to $60 \mathrm{~mJ}$ per pulse. The minimum crater size is $10 \mu \mathrm{m}$. The details of the LA system, optics, $\alpha$-box-installation, shielding and ablation cell design have recently been reported [38].
Inductively coupled plasma mass spectrometry

For more than 10 years the isotopic and elemental analysis of nuclear fuel samples at PSI has been performed using a quadrupole-based ICP-MS instrument (PQ2+, VG Elemental, UK). Since the analytical performance of such an ICP-MS instrument is limited for precise isotope ratio measurements, a MC-ICP-MS instrument (Neptune, Thermo Fisher Scientific, Germany) was installed in 2001 in the PSI hot laboratory and has been used for precise isotopic characterization of different materials in combination with the HPLC and the LA system [38, 41]. For the handling and analysis of nuclear fuel cycle materials the sample-introduction system of the MC-ICP-MS instrument (peristaltic pump, nebulizer, spray chamber, torch box and cones) is encapsulated within a glove box.

All isotope ratio measurements have to be corrected for mass bias by normalization to an invariant or known isotope ratio of the same element (internal correction) or to a well-characterized isotope reference material (external correction). Since internal corrections are not applicable for irradiated nuclear fuel samples, a bracketing procedure between samples and well-characterized reference materials was applied for mass bias corrections in this study (NISTSRM 100 for U, NIST-SRM 948 for $\mathrm{Pu}$ and a singleelement $\mathrm{Nd}$ standard solution from SPEX which is well characterized by TIMS).

\section{Results and discussion}

Burn-up determination by HPLC-MC-ICP-MS

The burn-up of nuclear fuel is one of the most important parameters that has to be determined in the frame of PIE 
experiments. It is proportional to the quotient of the number of fissions $N_{\mathrm{F}}$ and the number of heavy metal atoms $N_{\mathrm{M}}^{0}$ ( $\mathrm{U}$ and $\mathrm{Pu}$ ) which were present in the fuel before irradiation. The burn-up is given in percentage of fissions per initial metal atom (FIMA):

$\% F I M A=\frac{N_{\mathrm{F}}}{N_{\mathrm{M}}^{0}} \times 100$.

The experimental determination of the burn-up involves the analysis of the total heavy-element composition after irradiation and the concentration of a suitable fission product used as a burn-up monitor, e.g. ${ }^{148} \mathrm{Nd}$, as described in the ASTM standard method [23]. The number of fissions $N_{\mathrm{F}}$ is calculated according to Eq. (2):

$N_{\mathrm{F}}=\frac{N_{N d 148}}{Y_{N d 148}}$,

where $N_{\mathrm{Nd} 148}$ is the number of ${ }^{148} \mathrm{Nd}$ atoms and $Y_{\mathrm{Nd} 148}$ is the effective fission yield of ${ }^{148} \mathrm{Nd}$. The effective fission yield of ${ }^{148} \mathrm{Nd}$ has to be calculated by weighting the yields for ${ }^{148} \mathrm{Nd}$ from the four main fissionable nuclides $\left({ }^{235} \mathrm{U}\right.$, ${ }^{238} \mathrm{U},{ }^{239} \mathrm{Pu},{ }^{241} \mathrm{Pu}$ ) with the contributions of these nuclides for the corresponding fuel type $\left(\mathrm{UO}_{2}\right.$ or $\left.\mathrm{MOX}\right)$ for each individual fuel sample [42]. The effective fission yields increase slightly with burn-up for both $\mathrm{UO}_{2}$ and MOX, mostly because of the increasing contribution of ${ }^{241} \mathrm{Pu}$. Owing to neutron capturing of ${ }^{147} \mathrm{Nd}$, some extra ${ }^{148} \mathrm{Nd}$ is produced, whereas some ${ }^{148} \mathrm{Nd}$ is also destroyed by the same effect. Typically, no corrections for these minor contributions are performed. Estimations of the neutron capturing processes have indicated that the effect on the number of ${ }^{148} \mathrm{Nd}$ atoms is in the range of below $1 \%$ for MOX and below $2 \%$ for $\mathrm{UO}_{2}$ fuel. The relative contribution of capture in ${ }^{147} \mathrm{Nd}$ is almost independent of the burn-up, whereas the fraction of ${ }^{148} \mathrm{Nd}$ destroyed increases linearly with burn-up.

Consequently, the characterization of the burn-up includes the mass-spectrometric analysis of the concentrations of $\mathrm{U}, \mathrm{Pu}$ and ${ }^{148} \mathrm{Nd}$. The quantification is carried out by isotope dilution, which is known as the most precise quantification method for mass-spectrometric analyses.

$\mathrm{U}$ and $\mathrm{Pu}$ have isobaric interferences with each other and with other actinides $\left({ }^{238} \mathrm{U} /{ }^{238} \mathrm{Pu},{ }^{241} \mathrm{Pu} /{ }^{241} \mathrm{Am},{ }^{242} \mathrm{Pu} /{ }^{242} \mathrm{Am}\right.$, ${ }^{244} \mathrm{Pu} /{ }^{244} \mathrm{Cm}$ ), whereas $\mathrm{Nd}$ has interferences from other lanthanides $\left({ }^{142} \mathrm{Ce},{ }^{144} \mathrm{Ce},{ }^{148} \mathrm{Sm},{ }^{150} \mathrm{Sm}\right)$. The classical method for burn-up determination involves slow offline column techniques in order to isolate $\mathrm{Nd}, \mathrm{Pu}$ and $\mathrm{U}$ from the interfering elements. In order to circumvent these time-consuming separations and to minimize the exposure to high dose rates for the operator, an online coupled HPLC-MC-ICP-MS system was established at the PSI hot laboratory.

The online HPLC separation developed for $\mathrm{Pu}$ and $\mathrm{U}$ proved to be sufficient to resolve the isobaric interference between ${ }^{238} \mathrm{Pu}$, which is normally present at trace concentrations, and ${ }^{238} \mathrm{U}$ as the main component of $\mathrm{UO}_{2}$ and $\mathrm{MOX}$ fuels [14]. A detailed comparison of the precision for steady-state and transient signals has been given for the HPLC-MC-ICP-MS system described [41]. Generally it can be stated that the external reproducibility for transient signals is less than an order of magnitude lower compared with that for steady-state signals.

In order to determine the burn-up monitor ${ }^{148} \mathrm{Nd}$ it is necessary to separate this nuclide from the interfering isotope ${ }^{148} \mathrm{Sm}$. In aqueous solutions, the group of lanthanides is present as strongly hydrated trivalent cations. Because of their similar ionic properties they cannot be separated easily by cation exchange. With use of an appropriate chelating agent such as $\alpha$-hydroxyisobutyric acid, the selectivity of the separation can be increased [27].

Figure 2 shows a typical chromatographic separation of $\mathrm{Nd}$ from the interfering lanthanides in a MOX fuel sample as well as the isotope ratios ${ }^{148} \mathrm{Nd} /{ }^{150} \mathrm{Nd}$ and ${ }^{148} \mathrm{Sm} /{ }^{150} \mathrm{Sm}$ on the separated peaks, respectively. Whereas ${ }^{148} \mathrm{Nd}$ and ${ }^{150} \mathrm{Nd}$ are mainly produced by fission, the ${ }^{148} \mathrm{Sm}$ and ${ }^{150} \mathrm{Sm}$ atoms are predominantly formed as a result of neutron capturing of the precursor isotopes and their signals have therefore to be separated from the $\mathrm{Nd}$ signals. In contrast to the IonPac CS5A column based separation of $\mathrm{Nd}$ on standard materials reported in [41], an ion-pair chromatographic approach was used in the present study. This technique provides a much better baseline separation of the interfering lanthanides and less peak tailing, resulting in a higher precision of the isotope ratios of the nuclides that have interferences. Even a baseline separation between the interfering isotopes ${ }^{147} \mathrm{Sm}$ and ${ }^{147} \mathrm{Pm}$ can be achieved with the chosen chromatographic parameters. Since the concentrations of $\mathrm{Nd}$ and $\mathrm{Sm}$ and therefore the signal intensities are nearly identical, both elements could be quantitatively determined by isotope dilution within one chromatographic run. However, since the Neptune MC-ICP-MS instrument is only equipped with nine Faraday cups it is not possible to determine all isotopes of $\mathrm{Nd}$ and $\mathrm{Sm}$ with the same cup configuration. Mass bias correction using the exponential correction law was carried out on the mean values of the $\mathrm{Nd}$ isotope ratios after several individual injections of the unspiked and spiked fuel samples but not for each data point within one chromatographic run. The external reproducibility of the uncorrected $\mathrm{Nd}$ isotope ratios in fuel samples for repeated injections was determined to be in the range $0.01-0.05 \%(n=4)$, which is a significant improvement by at least 1 order of magnitude in comparison with the same Nd measurements carried out by quadrupole ICPMS. The corresponding Nd concentrations (milligrams of $\mathrm{Nd}$ per gram of fuel) determined by isotope dilution analysis typically have an uncertainty of $0.3-1.2 \%$ since these results are also influenced by the uncertainty of the 
Fig. 2 Chromatographic separation of the lanthanides in an irradiated mixed oxide (MOX) fuel sample (Gemini C18 column, 5- $\mu \mathrm{m}$ particle size, ion-pair reagent sodium octansulfonate; concentration of the analyzed solution $70 \mu \mathrm{g}$ fuel/g solution)

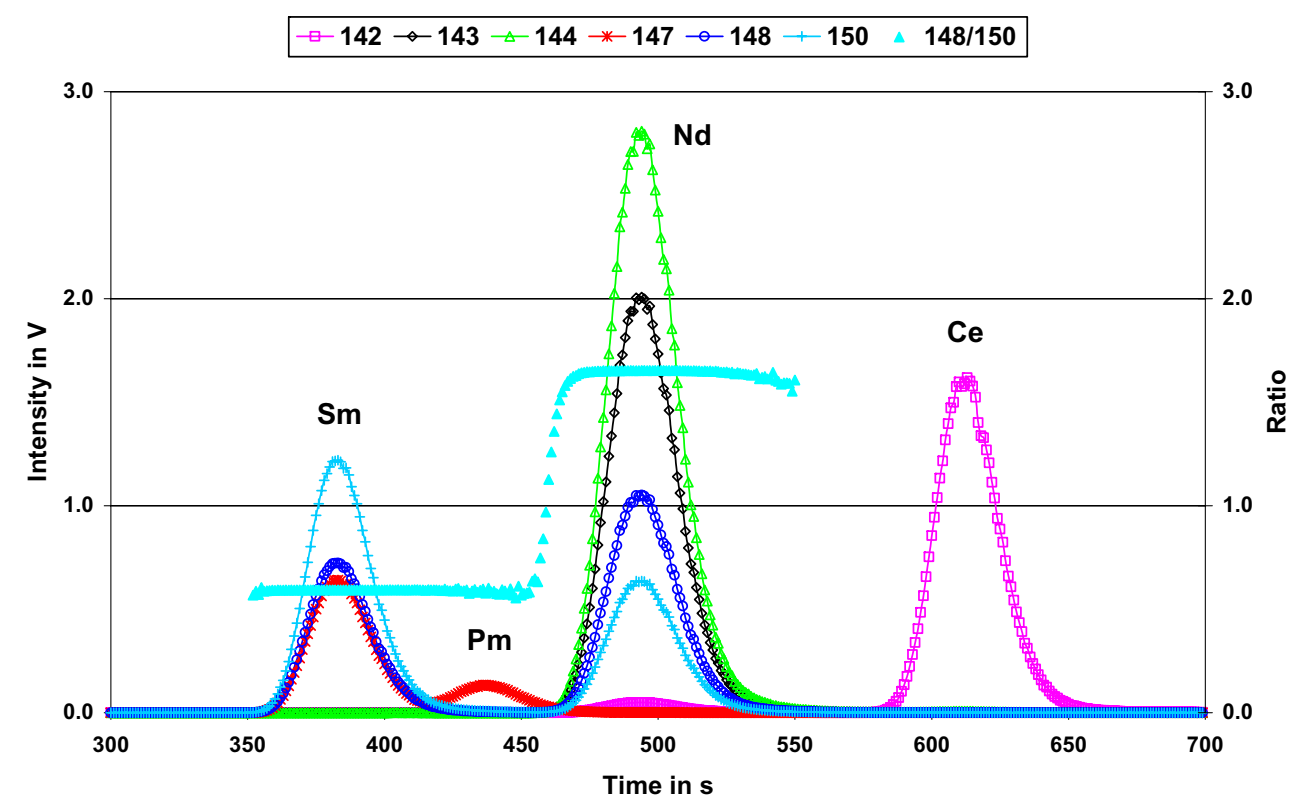

sample preparation (weighing), of the spike composition and concentration and of the concentration of the fuel solution. The $\mathrm{U}$ and $\mathrm{Pu}$ elemental concentrations, which are also necessary input data for the calculation of the fuel burn-up, are typically determined with a lower uncertainty in $\mathrm{UO}_{2}$ and MOX fuel samples $(0.1-0.5 \%)$ since these are the major components. However, since the highest impact on the uncertainty budget of the calculated burn-up is contributed by the uncertainty of the effective fission yield of the burn-up monitor ${ }^{148} \mathrm{Nd}\left(\mathrm{Y}_{\mathrm{Nd} 148}\right)$, the uncertainty of the burn-up value is limited to approximately $2.5 \%$.

In addition to the burn-up determination, most PIE programs are also aimed at the analysis of further actinides
(Am, Cm, Np) and major fission products (e.g., Cs, Sr, Sm, $\mathrm{Gd}, \mathrm{Eu}, \mathrm{Pm}, \mathrm{Tc}, \mathrm{Ru}, \mathrm{Rh}, \mathrm{Mo}$ ) of irradiated $\mathrm{UO}_{2}$ and $\mathrm{MOX}$ fuels. Whenever direct nebulization ICP-MS is not applicable owing to isobaric interferences, the online coupled HPLCMC-ICP-MS technique has to be applied. A typical separation of $\mathrm{Sr}$ and $\mathrm{Rb}$ from a MOX fuel sample on an IonPac CS12A column is illustrated in Fig. 3. The uncertainties of the isotopic composition and the corresponding elemental concentrations are comparable to the data presented for $\mathrm{Nd}$.

A special case is the determination of the fission product $\mathrm{Cs}$, since natural $\mathrm{Cs}$ is monoisotopic $\left({ }^{133} \mathrm{Cs}\right)$ and can therefore not be used as a reference material for mass bias correction. Other elements in the same mass range such as
Fig. 3 Chromatographic separation of $\mathrm{Sr}$ and $\mathrm{Rb}$ in an irradiated MOX fuel sample (isocratic elution with $200 \mathrm{mM} \mathrm{HCl}$ on a Dionex CS12A column; concentration of the analyzed solution $70 \mu \mathrm{g}$ fuel/g solution)

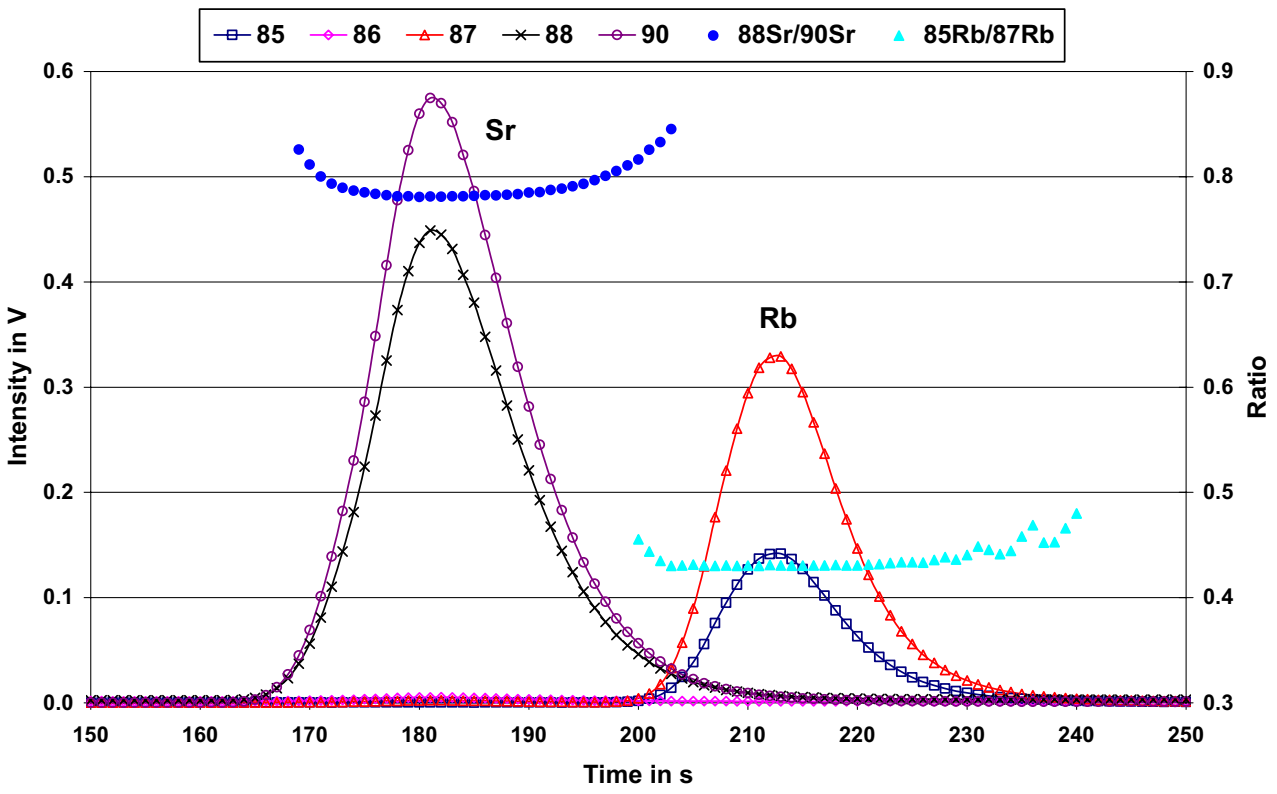




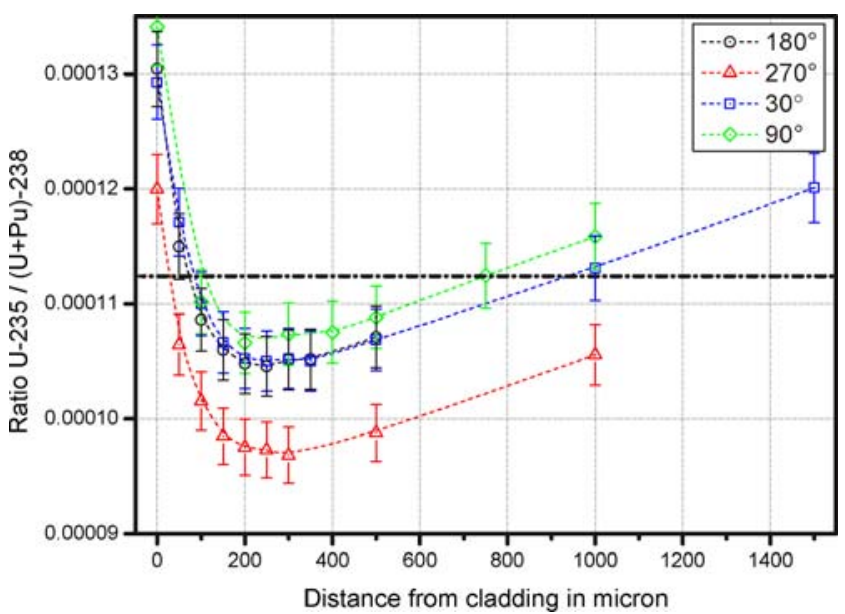

Fig. 4 Determination of the ${ }^{235} \mathrm{U} /{ }^{238} \mathrm{U}$ isotope ratio along the cross section of an irradiated $\mathrm{UO}_{2}$ fuel sample depending of the radial position on the fuel rod (the dashed line corresponds to the ${ }^{235} \mathrm{U} /{ }^{238} \mathrm{U}$ ratio determined by high-performance liquid chromatography multicollector inductively coupled plasma mass spectrometry, HPLC-MC-ICP-MS, in the dissolved fuel sample)

$\mathrm{Ba}$ (PSI approach) or $\mathrm{Eu}$ and $\mathrm{Sb}$ [43] have to be used for the external mass bias correction.

Application of LA-MC-ICP-MS for the investigation of fuel cycle materials

LA-ICP-MS is advantageous for isotopic determination in solid samples because it requires little or no sample preparation (thus minimizing the likelihood of sample or operator contamination when handling radioactive materials). But this technique has also some inherent drawbacks. Precise and accurate quantitative analyses depend on the availability of an internal standard with a known concentration within the sample and require certified reference materials that match the sample matrix. Typically, solid matrices are known to be inhomogeneous and, consequently, the precision achieved by LA-ICP-MS is usually significantly lower than for analyses on digested samples. However, when the spatial variation of an analyte is of interest (e.g., for the determination of hot spots) LA-ICP-MS is an advantageous technique.

During irradiation the nuclear fuel matrix changes significantly, with fission product concentrations varying along the fuel pellet cross section. Neutron-capture reactions and fuel-cladding interactions at the pellet periphery enhance the inhomogeneous distribution of fission products and actinides. Since these processes and the resulting nuclide distribution across the fuel pellet strongly depend on the actual burn-up, the selection of an internal standard with a known concentration and a homogenous distribution is very limited. Therefore, the utilization of LA-ICP-MS for quantitative analysis of nuclear fuel is significantly restricted. The inhomogeneous porosity of the fuel samples after irradiation further complicates the comparison of analyte signals from different laser spots, since a decrease of the nuclide intensity in the mass spectrometer may be contributed by a lower spatial analyte concentration in the sample or from less ablated material. Therefore, the use of LA-ICP-MS for nuclear fuel samples represents a challenging approach and will probably be limited to only a few selected applications, such as the determination of fission gas inclusions in the fuel matrix [40] or the investigation of isotope ratios of fission products and actinides along the fuel cross section.

In Figs. 4 and 5 the local determination of the isotope ratios for $\mathrm{U}$ and $\mathrm{Pu}$ by LA-MC-ICP-MS is shown close to the fuel-cladding interface of a high-burn-up $\mathrm{UO}_{2}$ fuel sample. During the analysis of a dissolved fuel sample from the same fuel rod by HPLC-MC-ICP-MS the concentration ratio between ${ }^{238} \mathrm{U}$ and the interfering nuclide ${ }^{238} \mathrm{Pu}$ was determined to be more than 750 . Therefore, the influence of ${ }^{238} \mathrm{Pu}$ on the $\mathrm{U}$ isotope ratio shown in Fig. 4 can be neglected. The general trend of the $U$ isotope ratios versus the distance from the cladding on the four different sampling positions is reproducible. However, a shift of the absolute values can be observed depending on the radial position, which is related to the influence of the adjacent fuel rods in the bundle. The results for the $\mathrm{Pu}$ isotope ratios (Fig. 5) are in good agreement with analyses performed by EPMA and SIMS on the same fuel rod (unpublished data) and also coincide with the data measured by HPLC-MC-ICP-MS on a dissolved fuel sample. However, the influence of ${ }^{241} \mathrm{Am}$ on the signal at mass 241 cannot be neglected since the concentration of ${ }^{241} \mathrm{Pu}$ in this sample is only about 25 times higher than the ${ }^{241} \mathrm{Am}$ concentration (determined in a dissolved fuel sample). This fact further complicates the interpretation of the distribution profile for isotopes that

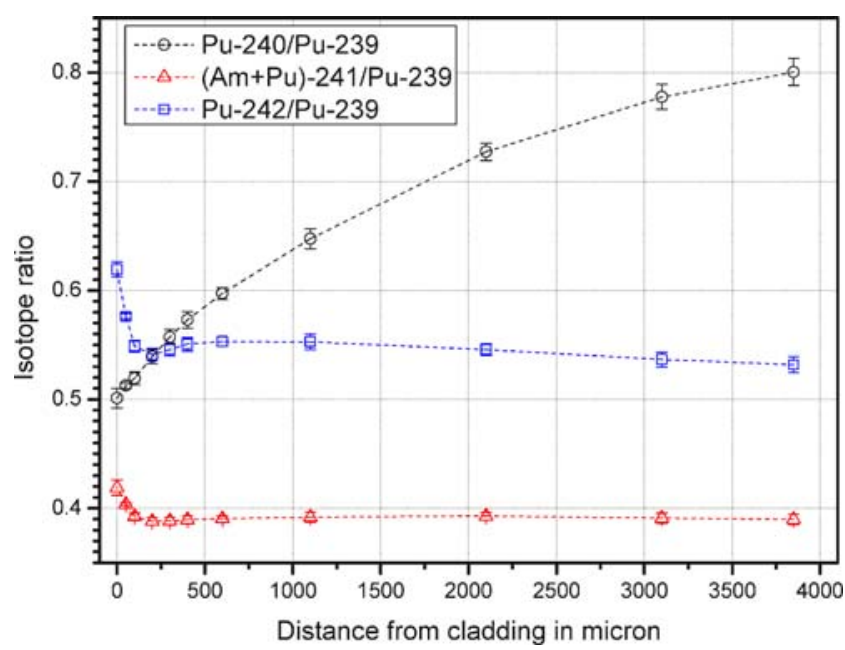

Fig. 5 Determination of $\mathrm{Pu}$ isotope ratios along the cross section of an irradiated $\mathrm{UO}_{2}$ fuel sample, radial position $90^{\circ}$ (for comparison, the ${ }^{242} \mathrm{Pu} /{ }^{239} \mathrm{Pu}$ ratio of a dissolved fuel sample was determined to be $0.541 \pm 0.001$ by HPLC-MS-ICP-MS) 
have interference from other nuclides and restricts direct LAICP-MS measurements to isotopes without interference. Because of the lack of a certified reference material and a suitable and homogeneously distributed internal standard, the direct quantification of $\mathrm{U}$ or $\mathrm{Pu}$ in such a sample matrix is not possible by LA.

Whereas nuclear fuel is a comparably difficult sample matrix for LA, other activated materials from the nuclear fuel cycle can be analyzed quantitatively with less constraint. One of the major topics regarding the fuel integrity within boiling water reactors is the problem of stress corrosion cracking (SCC) of recirculation piping and stainless steel reactor internals. To mitigate $\mathrm{SCC}$, the water chemistry can be changed in order to lower the electrochemical corrosion potential. This is normally achieved by adding hydrogen or by the NobleChem ${ }^{\mathrm{TM}}$ technology (General Electrics). During this process noble metals $(\mathrm{Pt} / \mathrm{Rh})$ are added to the feed water of the reactor, deposit on the reactor inner surfaces and act as electrocatalysts that efficiently recombine $\mathrm{O}_{2}$ and $\mathrm{H}_{2} \mathrm{O}_{2}$ with $\mathrm{H}_{2}$ on metal surfaces. In order to study the transport, distribution and deposition behavior of $\mathrm{Pt}$ and $\mathrm{Rh}$ on the reactor internals, LA-ICP-MS is successfully used at PSI to quantify such thin noble metal layers on activated steel samples from nuclear power plants [44]. It could be shown that the setup can achieve detection limits lower then $0.003 \mu \mathrm{g} / \mathrm{cm}^{2}$ for both noble metals.

\section{Conclusions}

An overview of typical applications of MC-ICP-MS (solution nebulization with or without HPLC coupling and direct solid analysis using LA) for the investigation of highly radioactive materials at the PSI hot laboratory was given. In addition, the determination of the fuel burn-up by HPLC-MC-ICP-MS and the determination of actinide isotope ratios by LA-MC-ICP-MS were discussed in detail. Both analytical techniques fulfill the requirements for the characterization of nuclear fuel cycle materials and are applied to improve the understanding of fundamental processes during the irradiation of nuclear fuel.

Nevertheless, the physical and chemical characteristic of irradiated nuclear fuel samples (inhomogeneous nuclide distribution and porosity) strongly restricts the application of LA-ICP-MS for quantitative analysis of this matrix.

Major advantages of online coupled HPLC-ICP-MS techniques compared with the conventional TIMS technique are the simplified sample preparation procedure (which is very important especially for radioactive samples with a high dose rate), the sample throughput and the enhanced ionization efficiency for elements with high ionization potentials. As shown in international PIE programs managed by Belgonucléaire, the precision and accuracy demonstrated by the MC-ICP-MS system is comparable to that of the classically used TIMS technique (confidential unpublished data). HPLC-ICP-MS combinations are beneficial owing to the separation of the sample matrix from the analyte elements. Particularly for the determination of trace elements in a highly concentrated matrix (as fission products in $\mathrm{UO}_{2}$ or $\mathrm{MOX}$ fuel), the online separation of the matrix allows significantly lower detection limits owing to reduced signal suppression typically observed in presence of highly concentrated matrix elements.

The results show that the ICP is a powerful excitation source, which fulfills in combination with MS most of the requirements of a standard method for the characterization of radioactive materials. However, an appropriate selection of the most suitable technique or instrument (solution nebulization with/without HPLC or LA coupled to quadrupole, collision/reaction cell, sector-field ICP-MS or MC-ICP-MS), currently not available within one single configuration, is necessary to provide precise and accurate analytical data for nuclear fuel cycle materials.

Acknowledgements The LA samples were investigated in the frame of a core materials behavior project which was supported financially by swissnuclear. The authors would like to thank C. Hellwig, M. Horvath (PSI) and D. Günther (ETH Zürich) for their contributions to this work, the surface analysis group at PSI, H.P Linder and M. Krois for the preparation of the fuel samples and the two reviewers for their critical comments.

\section{References}

1. Murphy BD, Primm RT (2002) Nucl Sci Eng 142:258-269

2. Riglet C, Provitina O, Dautheribes JL, Revy D (1992) J Anal At Spectrom 7:923-927

3. Garcia Alonso JI, Babelot JF, Glatz JP, Cromboom O, Koch L (1993) Radiochim Acta 62:71-79

4. Leloup C, Marty P, Dall'ava D, Perdereau M (1997) J Anal At Spectrom 12:945-950

5. Betti M (2000) Microchem J 67:363-373

6. Becker JS (2005) Int J Mass Spectrom 242:183-195

7. Henry R, Koller D, Liezers M, Farmer OT, Barinaga C, Koppenaal DW, Wacker J (2001) J Radioanal Nucl Chem 249:103-108

8. ASTM International (2005) Method C1637-06. In: Annual book of ASTM standards, vol 12.01 (nuclear energy). ASTM International, West Conshohocken

9. ASTM International (2005) Method C1345-96R01. In: Annual book of ASTM standards, vol 12.01 (nuclear energy). ASTM International, West Conshohocken

10. ASTM International (2005) Method C1614-05. In: Annual book of ASTM standards, vol 12.01 (nuclear energy). ASTM International, West Conshohocken

11. ASTM International (2005) Method C1474-00. In: Annual book of ASTM standards, vol 12.01 (nuclear energy). ASTM International, West Conshohocken

12. Halliday AN, Lee DC, Christensen JN, Walder AJ, Freedman PA, Jones CE, Hall CM, Yi W, Teagle D (1995) Int J Mass Spectrom Ion Processes 146/147:21-33 
13. Rehkämper M, Schönbächler M, Stirling CH (2001) Geostand Newsl 25:23-40

14. Günther-Leopold I, Kobler Waldis J, Wernli B, Kopajtic Z (2005) Int J Mass Spectrom 242:197-202

15. Brennetot $\mathrm{R}$, Becquet $\mathrm{AL}$, Isnard $\mathrm{H}$, Caussignac $\mathrm{C}$, Vailhen $\mathrm{D}$, Chartier F (2005) J Anal At Spectrom 20:500-507

16. Isnard $\mathrm{H}$, Brennetot $\mathrm{R}$, Caussignac $\mathrm{C}$, Caussignac $\mathrm{N}$, Chartier $\mathrm{F}$ (2005) Int J Mass Spectrom 246:66-73

17. Wolf SF (1998) J Radioanal Nucl Chem 235:207-212

18. Garcia Alonso JI, Sena F, Koch L (1994) J Anal At Spectrom 9:1217-1222

19. Garcia Alonso JI, Thoby-Schultzendorff, Giovanonne B, Glatz JP, Pagliosa G, Koch L (1994) J Anal At Spectrom 9:1209-1215

20. Abousahl S, van Belle P, Eberle H, Ottmar H, Lynch B, Vallet P, Mayer K, Ougier M (2005) Radiochim Acta 93:147-153

21. Bienvenu P, Cassette P, Andreoletti G, Bé MM, Comte J, Lépy MC (2007) Appl Radiat Isot 65:355-364

22. Wolf SF, Tsai Y (2005) J Radioanal Nucl Chem 263:575-579

23. ASTM International (2005) Method E0321-96R05. In: Annual book of ASTM standards, vol 12.01 (nuclear energy). ASTM International, West Conshohocken

24. Garcia Alonso JI, Sena F, Arbore P, Betti M, Koch L (1995) J Anal At Spectrom 10:381-393

25. Röllin S, Kopajtic Z, Wernli B, Magyar B (1996) J Chromatogr A 739:139-149

26. Chartier F, Aubert M, Pilier M (1999) Fresenius J Anal Chem 364:320-327

27. Barrero Moreno JM, Garcia Alonso JI, Arbore P, Nicolaou G, Koch L (1996) J Anal At Spectrom 11:929-935

28. Betti M (1997) J Chromatogr A 789:369-379
29. Barrero Moreno JM, Betti M, Nicolaou G (1999) J Anal At Spectrom 14:875-879

30. Solatie D, Carbol P, Betti M, Bocci F, Hiernaut T, Rondinella VV, Cobos J (2000) Fresenius J Anal Chem 368:88-94

31. Röllin S, Eklund UB, Spahiu K (2001) Radiochim Acta 89: 757-763

32. Perna L, Bocci F, Aldave de las Heras L, De Pablo J, Betti M (2002) J Anal At Spectrom 17:1166-1171

33. Wolf SF, Bowers DL, Cunnane JC (2005) J Radioanal Nucl Chem 263:581-586

34. Vais V, Li C, Cornett J (2004) Anal Bioanal Chem 380:235-239

35. Kim CS, Kim CK, Martin P, Sansone U (2007) J Anal At Spectrom 22:827-841

36. Isnard $\mathrm{H}$, Aubert $\mathrm{M}$, Blanchet $\mathrm{P}$, Brennetot R, Chartier F, Geertsen V, Manuguerra F (2006) Spectrochim Acta B 61:150-156

37. Hollas S, Van Winckel S, Malmbeck R, Christiansen B, Glatz JP (2004) ICP Inf Newsl 30:644

38. Guillong M, Heimgartner P, Kopajtic Z, Günther D, GüntherLeopold I (2007) J Anal At Spectrom 22:399-402

39. Halicz L, Günther D (2004) J Anal At Spectrom 19:1539-1545

40. Horvath M, Guillong M, Izmer A, Kivel N, Restani R, GüntherLeopold I, Opitz Coutureau J, Hellwig C, Günther D (2007) J Anal At Spectrom. DOI 10.1039/b705533a

41. Günther-Leopold I, Wernli B, Kopajtic Z, Günther D (2004) Anal Bioanal Chem 378:241-249

42. Suyama K, Mochizuki H (2006) Ann Nucl Energy 33:335-342

43. Isnard H, Aubert M, Chartier F, Ducarme E, Tran B (2007) ICP Inf Newsl 32:1234

44. Kivel N, Günther-Leopold I, Hellwig C (2007) ICP Inf Newsl 32:1144 